\title{
EFFECT OF CHEMICAL REACTION ON MIXED CONVECTIVE NANOFLUID FLOW ON A VERTICAL PLATE WITH UNIFORM HEAT AND MASS FLUXES
}

\author{
H. MONDAL ${ }^{*}$, S.P GOQO and P. SIBANDA \\ School of Mathematics, Statistics and Computer Science \\ University of KwaZula-Natal \\ Private Bag X01, Scottsvile, Pietermaritzburg-3209, SOUTH AFRICA \\ E-mail: hiranmoymondal@yahoo.co.in \\ P. DE \\ Department of Mathematics, School of Advanced Sciences \\ VIT University, Chennai Campus \\ Chennai-600127, Tamil Nadu, INDIA
}

\begin{abstract}
The purpose of this paper is to consider a two dimensional free convective flow of a nanofluid due to the combined effects of thermal and mass diffusion in the presence of a chemical reaction of first order. The objective of the present investigation is to analyze the free convective flow in the presence of prescribed wall heat flux and mass flux condition. The governing equations of the linear momentum, energy equation and concentration are obtained in a dimensionless form by introducing a suitable group of similarity transformations. The transformed coupled non-linear ordinary differential equations are solved numerically by using appropriate boundary conditions for the various values of physical parameters. Computations are performed for a wide range of values of the various governing flow parameters of the velocity, temperature and species concentration profiles and results are presented graphically. Numerical results for the skin friction coefficient and local Nusselt number are also presented and analyzed in detail. The obtained results are compared with previously published work and are found to be in excellent agreement. The results are a very useful source of information for researchers on the subject of a free convective flow of a nanofluid. This paper illustrates chemical reaction effects on free convective flow of a nanofluid from a vertical plate with uniform heat and mass fluxes.
\end{abstract}

Key words: free convective flow, nanofluids, chemical reaction.

\section{Introduction}

A critical review of convective heat transfer of nanofluids can be found in the review article by Daungthongsuk and Wongwises [1]. Nanofluids are new kind of fluid consisting of uniformly dispersed and suspended nanometer-sized particles (called nanoparticles) or fibers in fluids. They have unprecedented thermal characteristics. They exhibit enhanced thermal properties, among them; higher thermal conductivity and heat transfer coefficients compared to the base fluids. Recent simulations of the cooling system of a large truck engine indicate that the replacement of the conventional engine coolant (ethylene glycol-water mixture) with a nanofluid would provide considerable benefits by removing more heat from the engine. The nanofluid would reduce the temperature, radiator size and pump size. Hence, there is considerable interest in the use of nanofluids for any process that requires cooling. Processing time could be reduced using nanoparticles in water compared to using water to cool. Keblinski et al. [2]

\footnotetext{
* To whom correspondence should be addressed
} 
examined nanofluids for thermal transport. Murshed et al. [3] studied thermophysical and electrokinetic properties of nanofluids. Phelan et al. [4] examined heat transfer applications for nanofluids. Heat transfer characteristics of nanofluids were studied by Trisaksri and Wongwises [5]. De et al. [6] investigated the influence of nanofluids on magnetohydrodynamic heat and mass transfer over a non-isothermal wedge with variable viscosity and thermal radiation. Albadr et al. [7] investigated heat transfer through a heat exchanger using \$Al_\{2\}O_\{3\}\$ nanofluid at different concentrations. Mirmasoumi and Behzadmehr [8] studied the effect of nanoparticles mean diameter on mixed convection heat transfer of a nanofluid in a horizontal tube. $\mathrm{Yu}$ and Choi [9] examined the role of interfacial layers in the enhanced thermal conductivity of nanofluids. Nandy et al. [10] studied the natural convection of nanofluids. Chemical reaction is a process involving one or more substances, characterized by a chemical change and yielding one or more products which are different from the reactants. A chemical change is defined as molecules attaching to one other to form larger molecules, molecules breaking apart to form two smaller molecules, or rearrangement of atoms within molecules. Chemical reactions can be termed as either a heterogeneous or homogeneous processes. This depends on whether they occur at an interface or as a single phase volume reaction. Homogeneous reactions are chemical reactions in which the reactants are in the same phase, while heterogeneous reactions have reactants in two or more phases. For example, a reaction between gases, liquids or solids is homogeneous. A reaction between a gas and a liquid, a gas and a solid, or a liquid and a solid is heterogeneous. Effects of chemical reaction heat and mass transfer on laminar flow along a semi infinite horizontal plate were examined by Anjali Devi and Kandasamy [11, 12]. They also studied the effects of chemical reaction, heat and mass transfer on non-linear MHD laminar boundary layer flow over a wedge with suction and injection. Chamkha [13] developed MHD flow of uniformly stretched vertical permeable surface in the presence of heat generation/ absorption and a chemical reaction.

Fairbanks and Wike [14] presented diffusion and chemical re-action in an isothermal laminar flow along a soluble flat plate. Fan et al. [15] investigated the similarity solution of mixed convection with chemical reaction over a horizontal moving plate. Ibrahim and Makinde [16] investigated MHD boundary layer flow of chemically reacting fluid with heat and mass transfer past a stretching sheet. Rajeswari et al. [17] studied chemical reaction, heat and mass transfer on nonlinear MHD boundary layer flow through a vertical porous surface in the presence of suction. Kandasamy et al. [18] studied the effects of chemical reaction, heat and mass transfer on non-linear laminar boundary-layer flow over a wedge with suction or injection. Mansour et al. [19] examined the effects of chemical reaction and thermal stratification on MHD free convective heat an mass transfer over a vertical stretching surface embedded in a porous media considering Soret and Dufour numbers. Mingchun et al. [20] developed the non thermal equilibrium model of the coupled heat and mass transfer in strong endothermic chemical reaction system of porous media. Patil et al. [21] investigated the effects of chemical reaction on mixed convection flow of a polar fluid through a porous medium in presence of internal heat generation. Very recently, Patil [22] developed chemical reaction.

To the best of author's knowledge, no previous study has been undertaken to examine the effects of chemical reaction with heat and mass transfer of a nanofluids over a semi-infinite vertical plate. The flow configuration is modeled as a vertical plate filled with nanofluid containing soluble and insoluble chemical materials. The transformed dimensionless governing equations are solved numerically. The effects of various physical parameters on velocity, temperature, concentration fields as well as on skin-friction coefficient and local Nusselt number are analyzed in details.

\section{Mathematical formulation}

We consider steady, laminar, two-dimensional mixed convection flow of a viscous incompressible nanofluid through a porous medium over a semi-infinite vertical porous plate. Figure 1 shows the coordinate system and the physical model for the flow configuration. The $x$-axis is taken along the vertical plate and $y$-axis is normal to it. The surface is maintained at a prescribed heat flux $q_{w}$ as well as a mass flux $m_{w}$. The concentration of diffusing species is assumed to be very small in comparison with other chemical species far 
from the surface $C_{\infty}$, and is infinitely small. Hence, the Soret and Dufour effects are neglected. However, the first-order homogeneous chemical reactions is assumed to take place in the flow. All thermo-physical properties of the fluid in the flow model are assumed to be constant except the density variations causing the buoyancy force represented by the body force term in the momentum equation. The boussinesq approximation is invoked for the fluid properties to relate density changes to temperature and concentration changes, and to couple in this way the temperature and concentration fields to the flow field (Schlichting, [23]). Under the above assumptions, the equations of conservation of mass, momentum, energy and concentration governing the problem of free convection boundary layer flow along a plate are given by (Patil [22]):

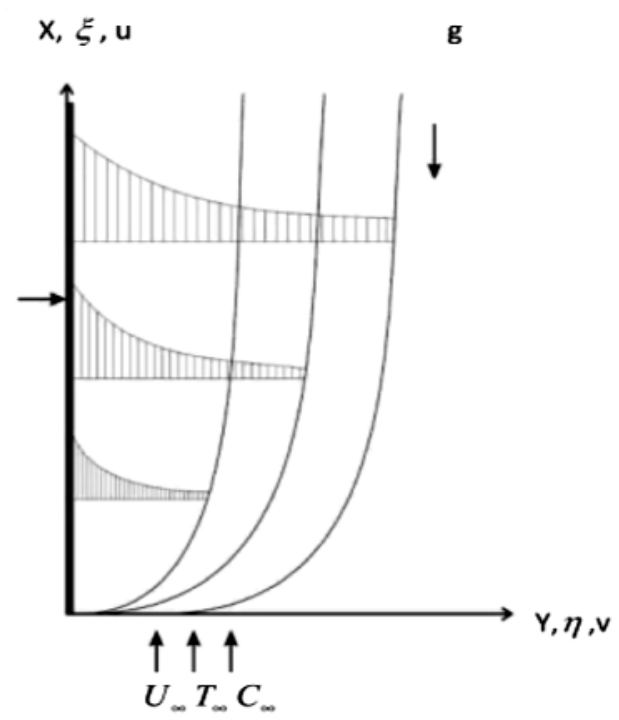

Fig.1. Flow model and coordinate system.

(i) conservation of mass

$$
\frac{\partial u}{\partial x}+\frac{\partial v}{\partial y}=0
$$

(ii) conservation of momentum

$$
u \frac{\partial u}{\partial x}+v \frac{\partial v}{\partial y}=v \frac{\partial^{2} u}{\partial y^{2}}+g\left[\beta_{T}\left(T-T_{\infty}\right)+\beta_{c}\left(C-C_{\infty}\right)\right]
$$

(iii) energy equation

$$
u \frac{\partial T}{\partial x}+v \frac{\partial T}{\partial y}=\frac{k}{\rho C_{p}} \frac{\partial^{2} T}{\partial y^{2}}+\tau\left[D_{B} \frac{\partial C}{\partial y} \frac{\partial T}{\partial y}+\frac{D_{T}}{T_{\infty}}\left(\frac{\partial T}{\partial y}\right)^{2}\right]
$$

(iv) mass diffusion of species equation

$$
u \frac{\partial C}{\partial x}+v \frac{\partial C}{\partial y}=D_{B} \frac{\partial^{2} C}{\partial y^{2}}+\left(\frac{D_{T}}{T_{\infty}}\right) \frac{\partial^{2} T}{\partial y^{2}}-k_{l}\left(C-C_{\infty}\right) .
$$

All of the parameters appearing in Eqs (2.1)- (2.4) are defined in the nomenclature section. 
The appropriate boundary conditions are

$$
\begin{aligned}
& y=0: \quad u=0, \quad-k \frac{\partial T}{\partial y}=q_{w}, \quad-D \frac{\partial C}{\partial y}=m_{w}, \\
& y \rightarrow \infty: u \rightarrow U_{\infty}, \quad T \rightarrow T_{\infty}, \quad C \rightarrow C_{\infty} .
\end{aligned}
$$
variables

In order to obtain similarity solution to the problem we introduce the following non-dimensional

$$
\begin{array}{lcc}
\xi=\frac{x}{L}, & \eta=\frac{\mathrm{Gr}^{1 / 5}}{L \xi^{1 / 5}} y, & \psi(x, y)=v \mathrm{Gr}^{1 / 5} \xi^{4 / 5} f(\xi, \eta), \\
\theta(\xi, \eta)=\frac{\left(T-T_{\infty}\right)}{\left(q_{w} / k\right) L \xi^{1 / 5}} \mathrm{Gr}^{1 / 5}, & \varphi(\xi, \eta)=\frac{\left(C-C_{\infty}\right)}{\left(m_{w} / D\right) L \xi^{1 / 5}} \mathrm{Gr}^{1 / 5}, \\
u=\frac{\partial \psi}{\partial y}=\frac{v}{L} \mathrm{Gr}^{2 / 5} \xi^{3 / 5} f^{\prime}, & v=\frac{\partial \psi}{\partial y}=-\frac{v}{L} \mathrm{Gr}^{1 / 5} \xi^{4 / 5}\left(\frac{4}{5} \frac{f}{\xi}+\frac{\partial f}{\partial \xi}+L f^{\prime} \eta_{x}\right)
\end{array}
$$

where $L$ is the characteristics length.

Defining the stream function in the usual way such that $u=\frac{\partial \psi}{\partial y}$ and $v=-\frac{\partial \psi}{\partial x}$ and substituting Eq.(2.6) in Eqs (2.2), (2.3) and (2.4), we obtain the following transformed equations

$$
\begin{aligned}
& f^{\prime \prime \prime}+\frac{4}{5} f f^{\prime \prime}-\frac{3}{5} f^{\prime 2}+\theta+\lambda \varphi=\xi\left[f^{\prime} \frac{\partial f^{\prime}}{\partial \xi}-\frac{\partial f}{\partial \xi} f^{\prime \prime}\right], \\
& \theta^{\prime \prime}+\frac{4}{5} \operatorname{Pr} f \theta^{\prime}-\frac{1}{5} \operatorname{Pr} f^{\prime} \theta+\operatorname{Pr} N b \theta^{\prime} \varphi^{\prime}+\operatorname{Pr} N t \theta^{\prime 2}=\operatorname{Pr} \xi\left[f^{\prime} \frac{\partial \theta}{\partial \xi}-\frac{\partial f}{\partial \xi} \theta^{\prime}\right], \\
& \varphi^{\prime \prime}+\frac{4}{5} \operatorname{Le} f \varphi^{\prime}-\frac{1}{5} \operatorname{Le} f^{\prime} \varphi-\operatorname{Le} \Delta \xi^{\frac{2}{5}} \varphi+\frac{N t}{N b} \theta^{\prime \prime}=\operatorname{Le} \xi\left[f^{\prime} \frac{\partial \varphi}{\partial \xi}-\frac{\partial f}{\partial \xi} \varphi^{\prime}\right] \\
& \text { where } \quad \mathrm{Gr}=\frac{g \beta_{T} q_{w} L^{4}}{k v^{2}}, \quad \mathrm{Gr}^{*}=\frac{g \beta_{c} m_{w} L^{4}}{D v}, \quad \lambda=\frac{\mathrm{Gr}^{*}}{\mathrm{Gr}}, \quad \operatorname{Pr}=\frac{\rho v C_{p}}{k}, \\
& \Delta=\frac{k_{1} L^{2}}{v \mathrm{Gr}^{2 / 5}}, \quad \mathrm{Le}=\frac{v}{D_{B}}, \quad N b=\frac{(\rho c)_{p} D_{B\left(C_{w}-C_{\infty}\right)}}{(\rho c)_{f v}}, \quad N t=\frac{(\rho c)_{p} D_{T\left(T_{w}-T_{\infty}\right)}}{(\rho c)_{f v T_{\infty}}},
\end{aligned}
$$

are the Grashof number due to temperature, Grashof number due to concentration, buoyancy ratio, Prandtl number, chemical reaction parameter, Lewis number, Brownian motion parameter and thermophoresis parameter, respectively.

The corresponding boundary conditions (2.5) reduce to the following non-dimensional form 


$$
\begin{aligned}
& \eta=0: \quad f^{\prime}=0, \quad \theta^{\prime}=-1, \quad \varphi^{\prime}=-1, \\
& \eta \rightarrow \infty \quad f^{\prime} \rightarrow 1, \quad \theta \rightarrow 0, \quad \varphi \rightarrow 0 .
\end{aligned}
$$

The quantities of physical interest, namely, the skin-friction coefficient, local Nusselt number and the local Sherwood number are defined, respectively, as

$$
\begin{aligned}
& C_{f x}=\frac{2 \mu}{\rho U^{2}} \frac{\partial u}{\partial y}=2 \mathrm{Gr}^{11 / 25} \xi^{1 / 5} f^{\prime \prime}(\xi, 0), \\
& C_{f x} \mathrm{Gr}^{-11 / 25}=2 \xi^{1 / 5} f^{\prime \prime}(\xi, 0), \\
& \mathrm{Nu}_{x}=\frac{h L}{k} \\
& \mathrm{Nu}_{x} \mathrm{Gr}^{-1 / 5}=\frac{1}{\theta(\xi, 0)} \\
& \mathrm{Sh}_{x}=\frac{h m L}{D}, \\
& \mathrm{Sh}_{x} \mathrm{Gr}^{-1 / 5}=\frac{1}{\varphi(\xi, 0)}
\end{aligned}
$$

where

$$
U=\frac{v \mathrm{Gr}^{2 / 5} \xi^{3 / 5}}{L}
$$

\section{Results and discussion}

Numerical solutions to study the various governing parameter effects of chemical reaction on a free convective flow of a nanofluid over a semi-infinite vertical plate in the presence of chemical reaction are reported. The results are presented graphically in Figs 2-12 and conclusions are drawn to analyze the effects of various physical quantities of interest on the velocity, temperature and concentration distribution as well as on the skin-friction coefficient and local Nusselt number. Comparisons of the present results with previously published works (see Tab.1) have been made and excellent agreement have been obtained.

Table 1. Comparison of $\mathrm{Nu}_{x} \mathrm{Gr}_{x}^{-1 / 5}$ for selected values of $\mathrm{Pr}$ to previously published results with $\Delta=0.0, \xi=1.0, \lambda=0.0, \mathrm{Nb}=0.1, N t=0.0, \mathrm{Le}=0.0$.

\begin{tabular}{|l|c|c|c|c|}
\hline Pr & Lee et al. [24] & Chang and Lee [25] & Patil [22] & Present Results \\
\hline 0.1 & 0.2632 & 0.2634 & 0.263914 & 0.26291 \\
0.7 & 0.4838 & 0.4838 & 0.483776 & 0.47910 \\
7.0 & 0.8697 & 0.8697 & 0.870026 & 0.87084 \\
\hline
\end{tabular}

Figures 2 illustrate the influence of the buoyancy parameter $\lambda$ on the velocity $f^{\prime}(\xi, \eta)$ profiles. For the aiding flow $(\lambda>0)$, the ratio of buoyancy forces shows the significant overshoot in the velocity profiles near the surfaces for lower and higher Prandlt numbers. Although, the magnitude of the overshoot increases 
with the ratio of the buoyancy forces parameter $\lambda(\lambda>0)$, it decreases as the Prandtl number Pr increases. The physical reason is that the buoyancy force $\lambda$ has a stronger effect more in smaller Prandtl number fluid due to the lower viscosity of the fluid. Hence, the velocity increases within the boundary layer due to combined effects of assisting buoyancy forces, acting as a favorable pressure gradient and the velocity overshoot occurs. For higher Prandtl numbers Pr, the overshoot is less present as compared to the lower Prandtl numbers. Because a higher Prandtl number Pr in more viscous fluid makes it less sensitive to the buoyancy forces.

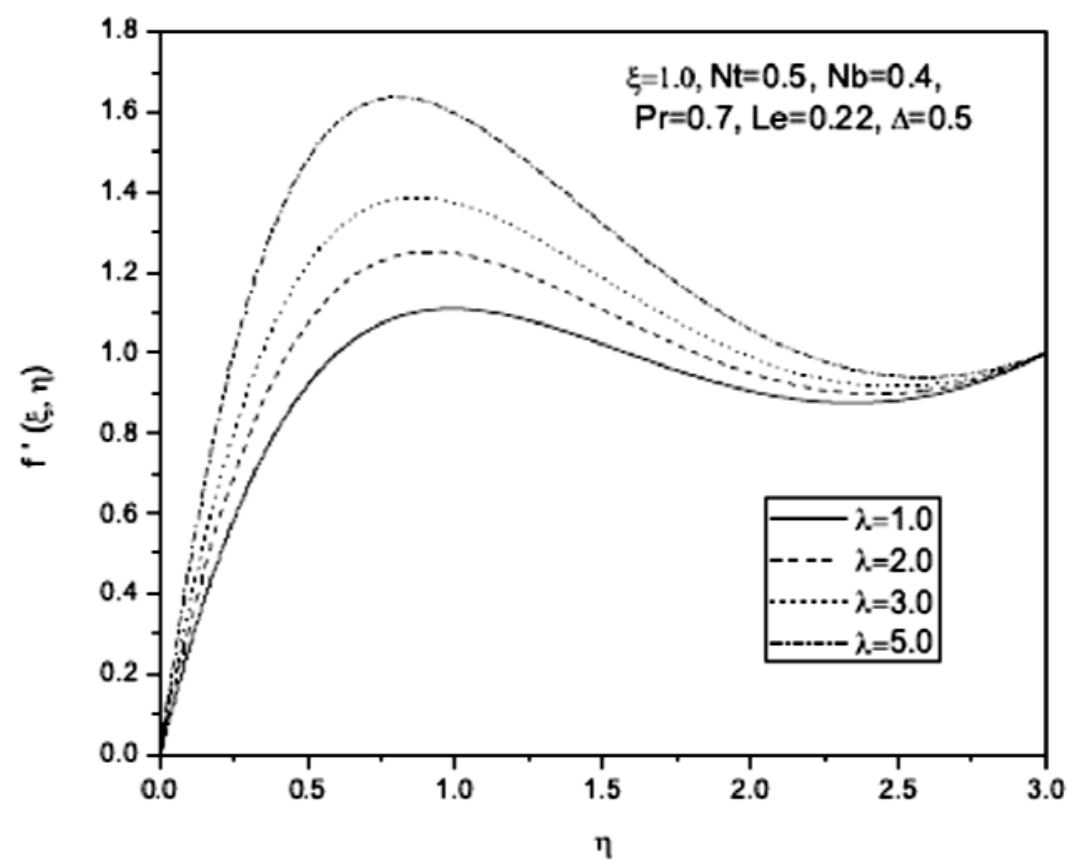

Fig.2. Velocity profile vs. $\eta$ for different values of $\lambda$.

The effects of the Brownian motion parameter $\mathrm{Nb}$ on velocity $f^{\prime}(\xi, \eta)$, temperature $\theta(\xi, \eta)$ and concentration $\varphi(\xi, \eta)$ are shown in Figs 3-5. The boundary layer profiles for the temperature are of the same form as in the case of regular heat transfer fluids. The fluid velocity and temperature in the boundary layer increases with the increase in the Brownian motion parameter $\mathrm{Nb}$. But the nanoparticle volume fraction profile decreases with the increase in the Brownian motion parameter $\mathrm{Nb}$. The Brownian motion serves to warm the boundary layer and simultaneously exacerbates particle deposition away from the fluid regime (onto the surface), thereby accounting for the reduced concentration magnitudes in Fig.8. The Brownian motion of nanoparticles can enhance thermal conduction via one of two mechanisms, either a direct effect owing to nanoparticles that transport heat or alternatively via an indirect contribution due to microconvection of the fluid surrounding individual nanoparticles. For small particles, the Brownian motion is strong and the parameter $\mathrm{Nb}$ will have high values, the converse is the case for large particles and clearly the Brownian motion does exert a significant enhancing influence on both temperature and concentration profiles. 


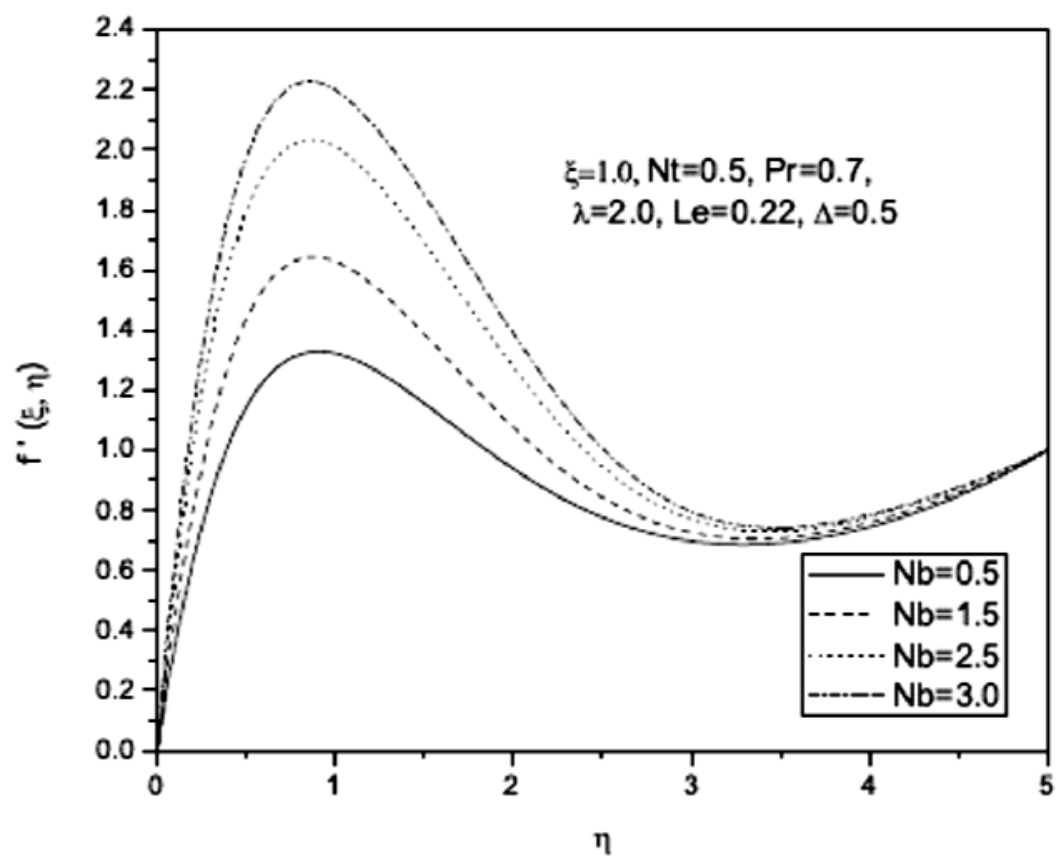

Fig.3. Veocity profile vs. $\eta$ for different values of $\mathrm{Nb}$.

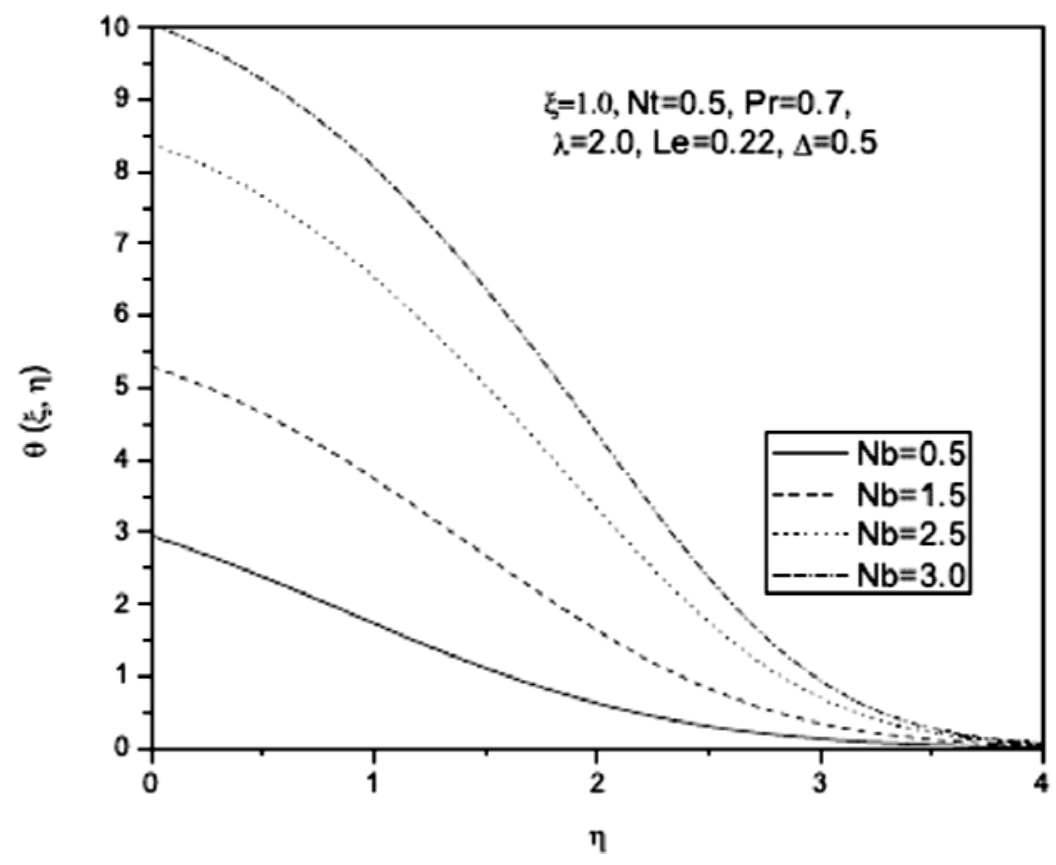

Fig.4. Temperature profile vs. $\eta$ for different values of $\mathrm{Nb}$. 


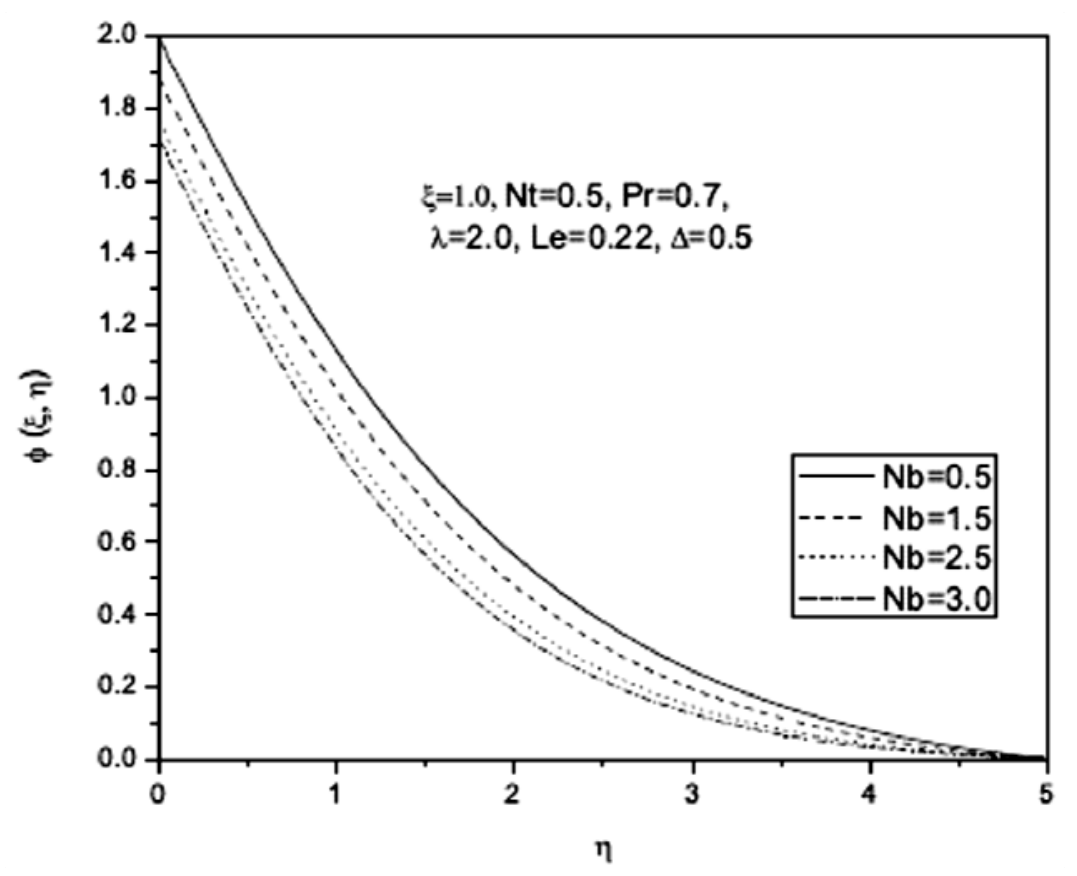

Fig.5. Concentration profile vs. $\eta$ for different values of $\mathrm{Nb}$.

Figures 6-8 illustrate profiles for velocity $f^{\prime}(\xi, \eta)$, temperature $\theta(\xi, \eta)$ and concentration $\varphi(\xi, \eta)$ distributions for various values of the thermophoretic parameter $N t$. It is noted that both the fluid velocity and temperature increases whereas the nanoparticle volume fraction decreases with an increase in $N t$. It is observed that an increase in $N t$ results in an increase of the temperature and concentration differences between the stretching surface and the ambient fluid. Thus, it is noticed that the velocity and temperature profiles increase but the thickness of the concentration boundary layer decreases with the increase of the values of the thermophoretic parameter $N t$. We notice that positive $N t$ indicates a cold surface while negative to a hot surface. For hot surfaces, thermophoresis tends to blow the nanoparticle volume fraction boundary layer away from the surface since a hot surface repels the sub-micron sized particles from it, thereby forming a relatively particle-free layer near the surface. As a consequence, the nanoparticles are distributed just outside. In particular, the effect of increasing the thermophoretic parameter $N t$ is limited to increasing slightly the wall slope of the nanoparticle volume fraction profiles but decreasing the nanoparticle volume fraction profiles.

Figures 9-10 display the variations of the velocity, temperature and concentration profiles for various values of the chemical reaction parameter $\Delta>0$ (species consumption or destructive chemical reaction). It is observed that the magnitude of the velocity and concentration distributions increase significantly when the chemical reaction parameter $\Delta$ is increased. An increase in the concentration of the diffusing species increases the mass diffusion and thus, in turn, the fluid velocity increases. On the contrary, for $\Delta>0$ (species generation or constructive chemical reaction), as $\Delta$ increases the velocity distribution decreases, so that the concentration reduces. 


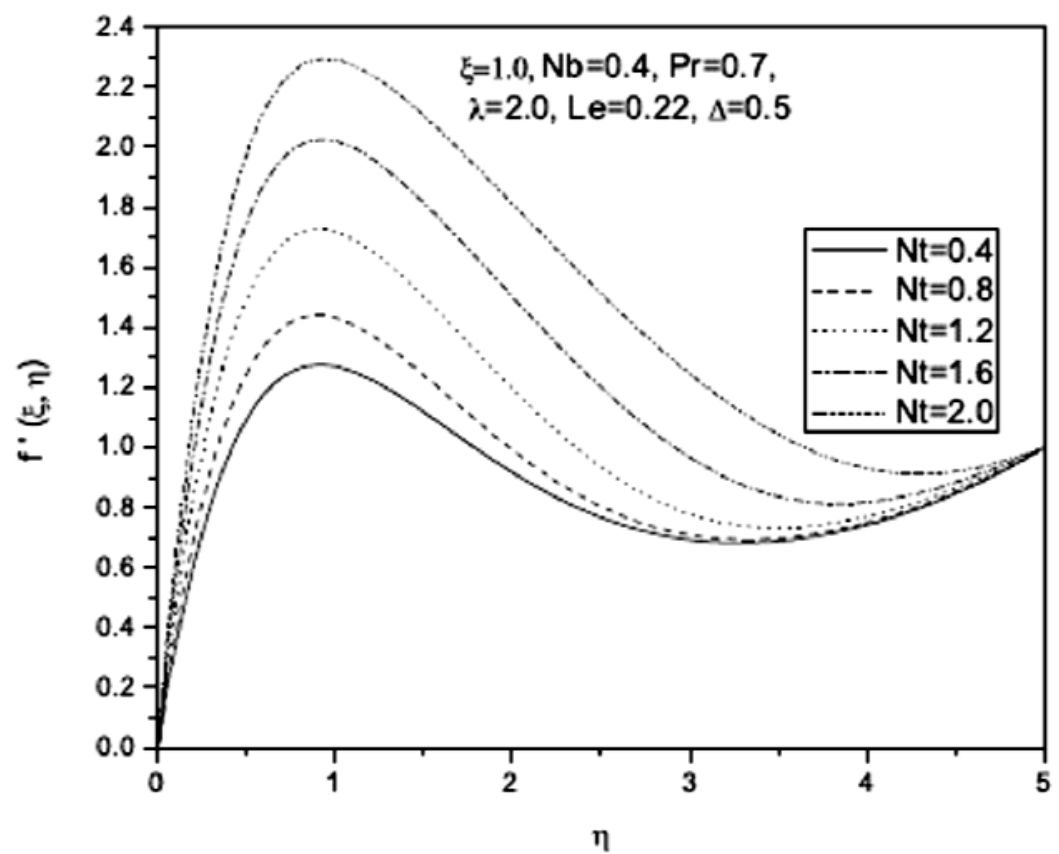

Fig.6. Velocity profile vs. $\eta$ for different values of $N t$.

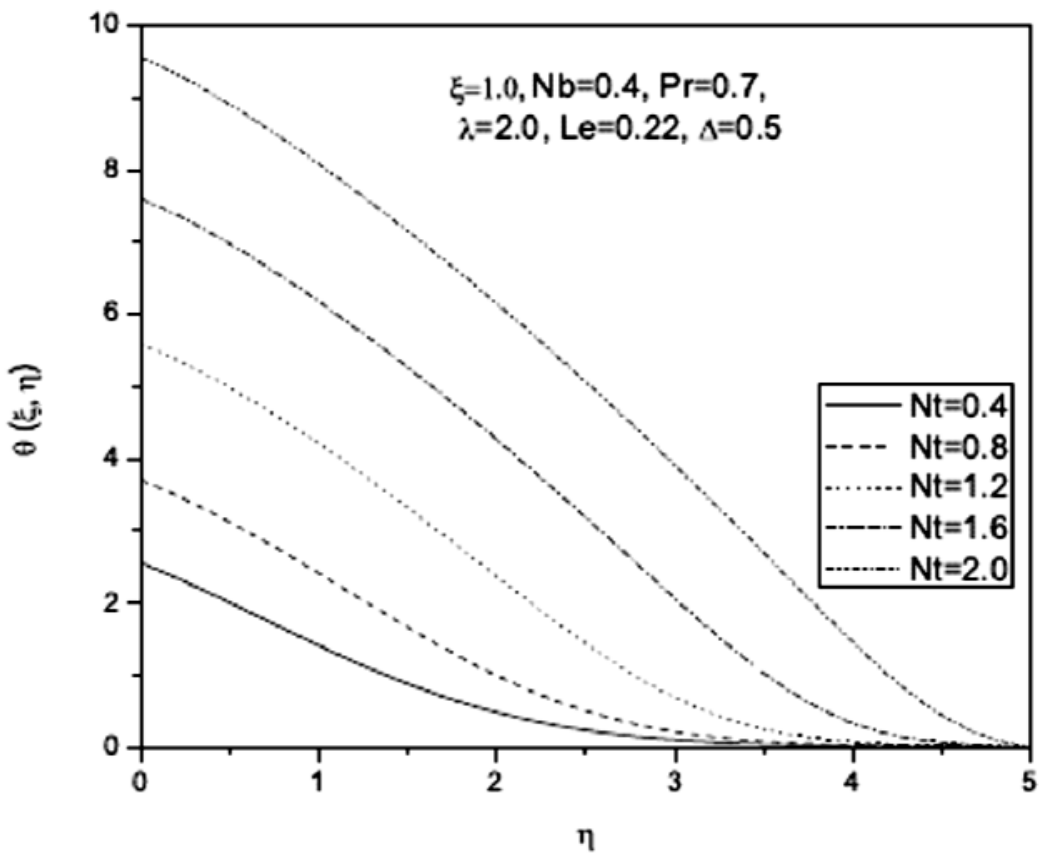

Fig.7. Temperature profile vs. $\eta$ for different values of $N t$. 


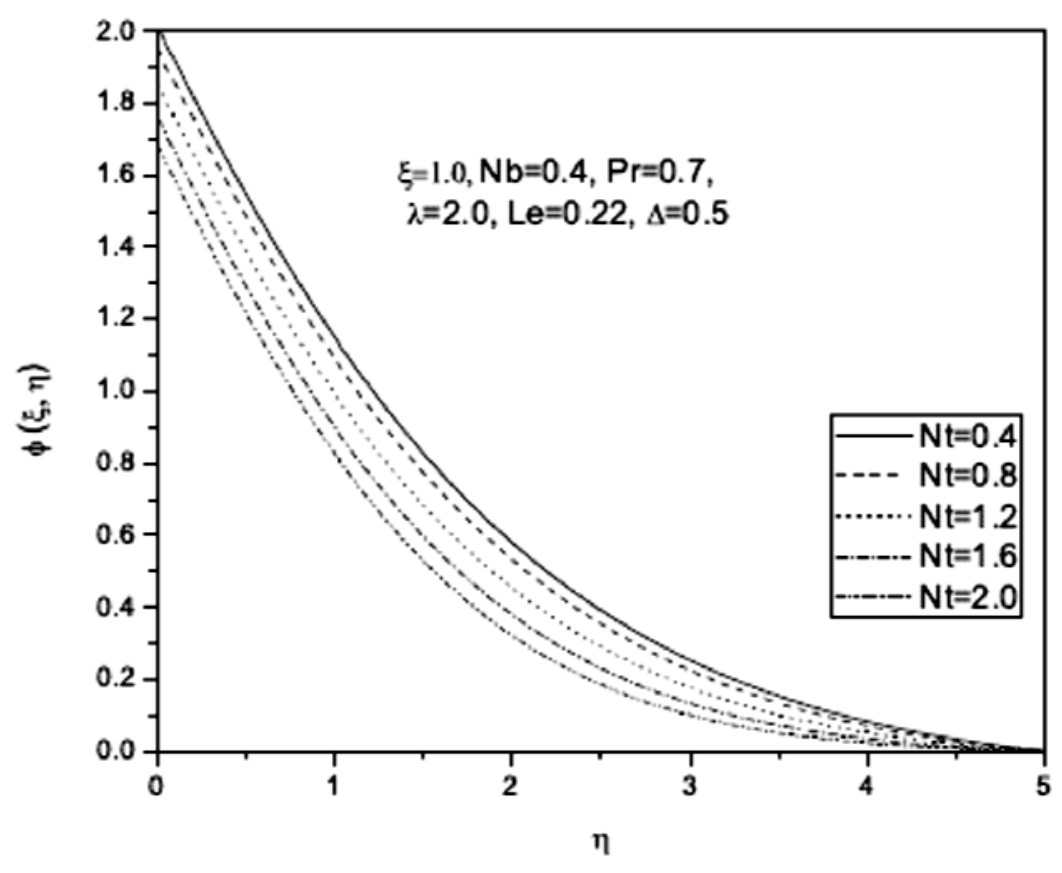

Fig.8. Concentration profile vs. $\eta$ for different values of $N t$.

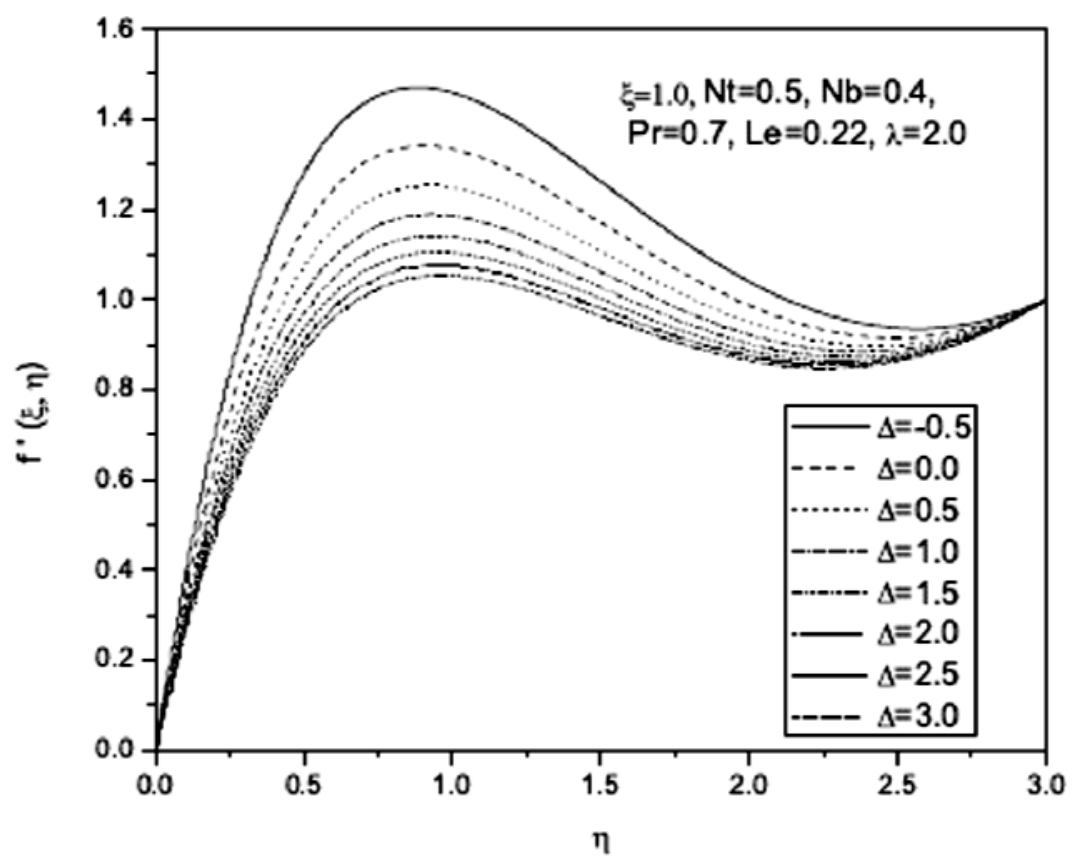

Fig.9. Velocity profile vs. $\eta$ for different values of $\Delta$. 


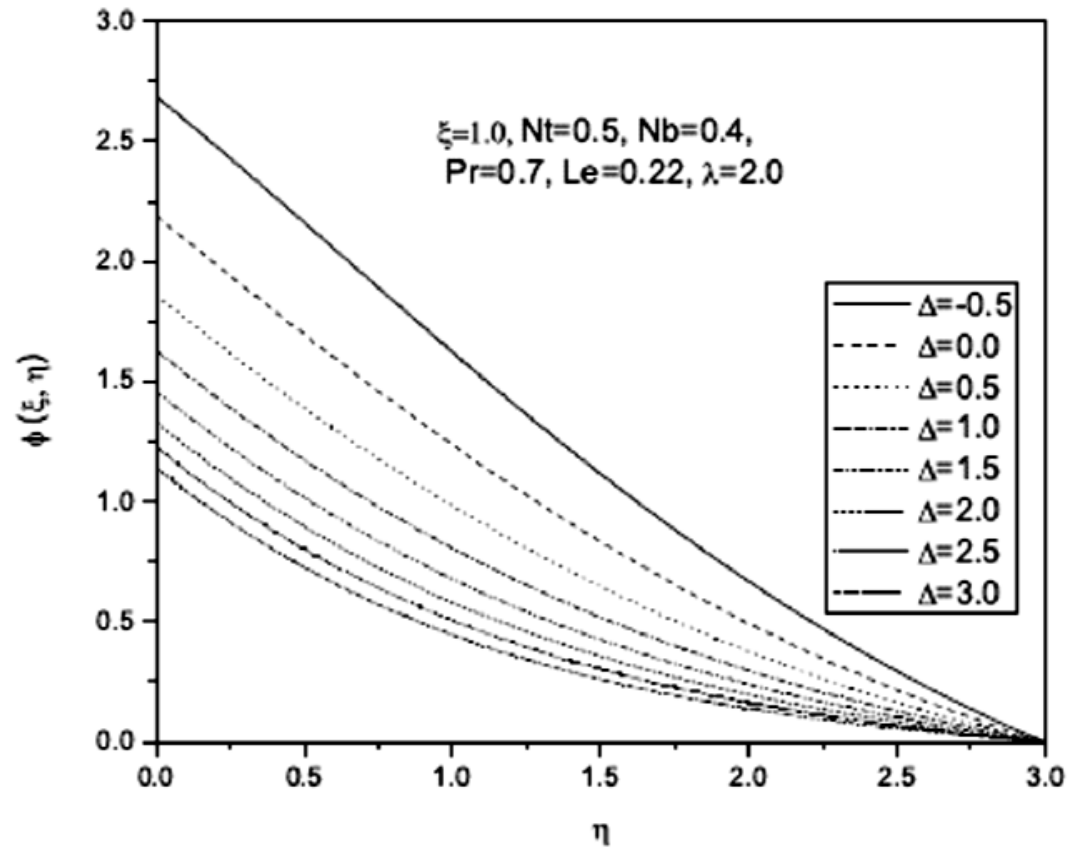

Fig.10. Concentration profile vs. $\eta$ for different values of $\Delta$.

Figures 11- 12 illustrate the effect of the skin friction coefficient and local Nusselt number with changes in the values of $\mathrm{Nb}$ and $N t$. It is observed that the effect of increasing $\mathrm{Nb}$ is to increase the skin friction coefficient and the local Nusselt number for all the values of $N t$.

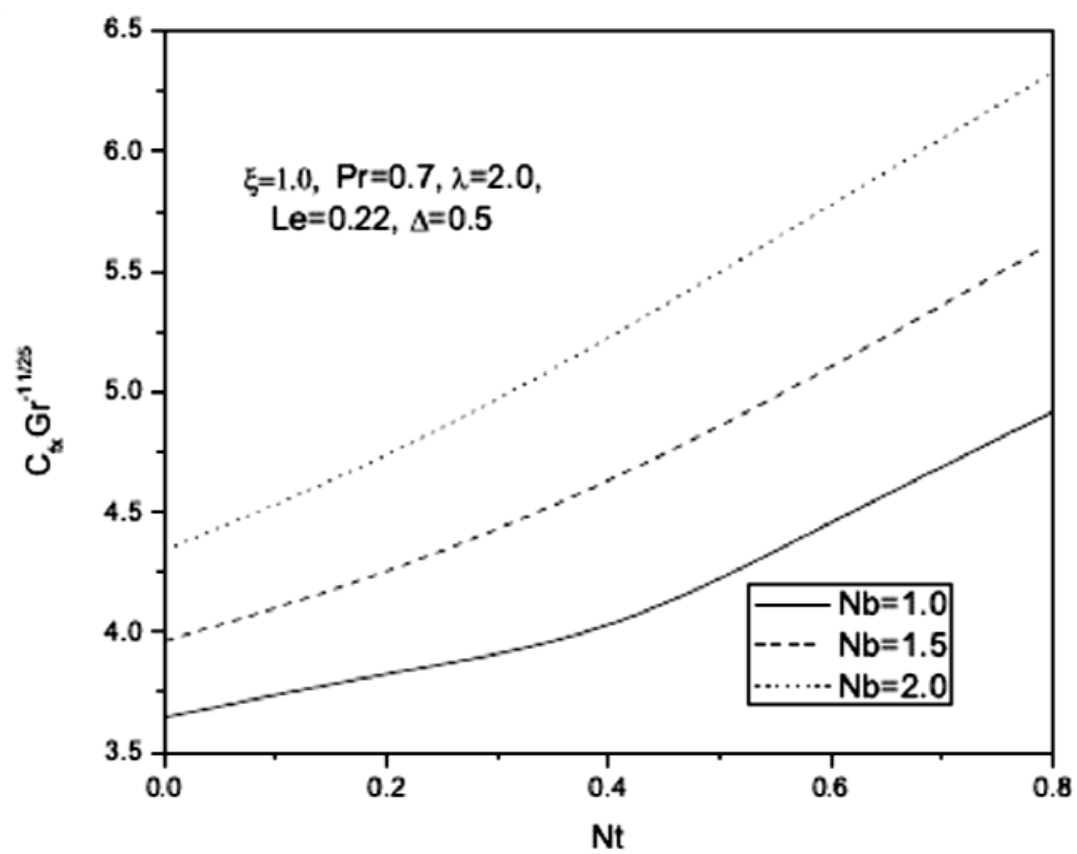

Fig.11. Variation in the skin-friction coefficient with $\mathrm{Nb}$ for various values of $N t$. 


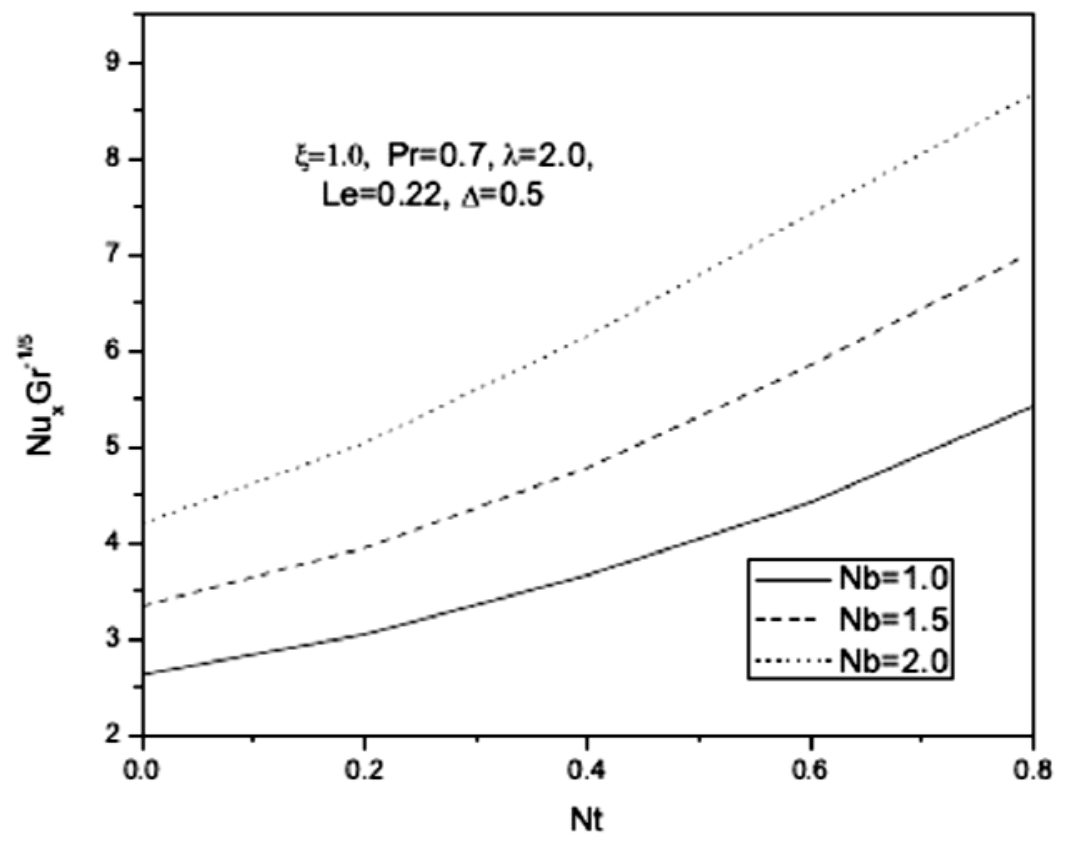

Fig.12. Variation in the Nusselt number with $\mathrm{Nb}$ for various values of $\mathrm{Nt}$.

\section{Conclusion}

A detailed numerical study has been carried out for a mixed convection flow of a nanofluid in the presence of chemical reaction. A transformed set of non-similar equations was obtained and were solved numerically. Comparisons with previously published results (see Tab.1) on special cases were made and found to be in excellent agreement. The effects of various physical parameters were examined in the boundary layer and analyzed in details.

The following conclusions are drawn from the numerical results:

(i) the effect of the ratio of buoyancy forces $\lambda$ caused overshoot in the velocity profiles;

(ii) the effect of the Prandtl number Pr increase in temperature profile;

(iii) the effect of the Brownian motion parameter $\mathrm{Nb}$ and thermophoretic parameter $N t$ increase for velocity and temperature profiles whereas a reverse effect can be seen for concentration profile;

(iv) the effect of the Lewis number Le and the buoyancy parameter $\lambda$ decreases the concentration boundary layer;

(v) the effects of the chemical reaction parameter $\Delta$ are found to decrease the velocity and concentration profiles;

(vi) the effects of the Brownian motion parameter $\mathrm{Nb}$ and thermophoresis parameter $\mathrm{Nt}$ are found to be significant for the skin-friction coefficient and local Nusselt number.

\section{Nomenclature}

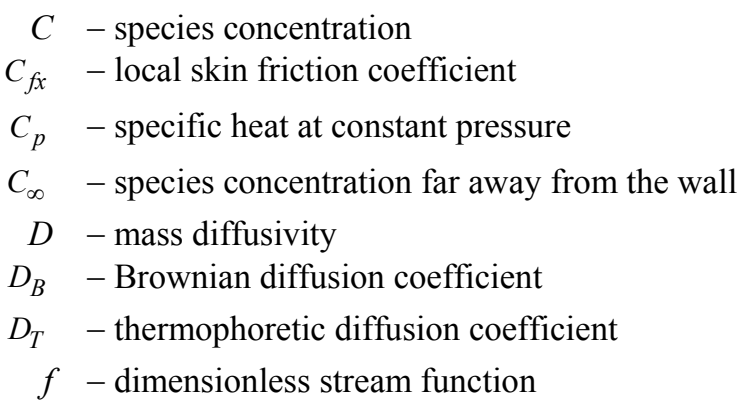




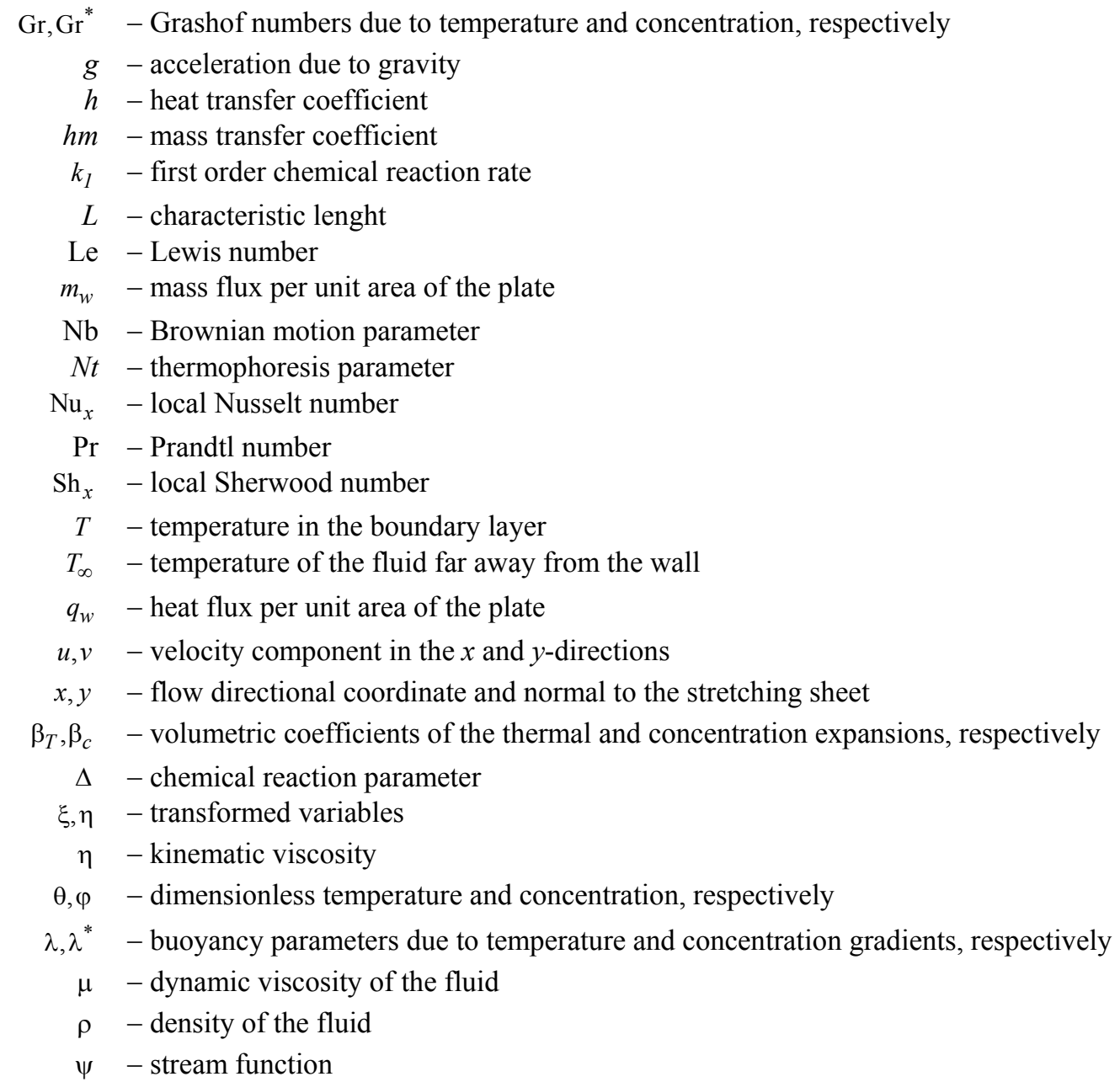

\section{Subscripts}

$C$ - of concentration

$T$ - of temperature

$w$ - conditions at the wall

$\xi, \eta \quad$ denote the partial derivatives w.r.t. these variables, respectively

$\infty \quad$ - free stream condition

\section{References}

[1] Daungthongsuk W. and Wongwises S. (2007): A critical review of convective heat transfer of nanofluids. Renewable and Sustainable Energy Reviews, vol.11, pp.797-817.

[2] Keblinski P., Eastman J.A. and Cahill D.G. (2005): Nanofluids for thermal transport. - Materials Today, vol.8, pp.36-44.

[3] Murshed S.M.S., Leong C. and Yang C. (2008): Thermophysical and electrokinetic properties of nanofluids: a critical review. - Applied Thermal Engineering, vol.28, pp.2109-2125.

[4] Phelan P.E., Bhattacharya P. and Prasher R.S. (2005): Nanofluids for heat transfer applications. - Annual Reviews of Heat Transfer, vol.14, pp.255-275.

[5] Trisaksri V. and Wongwises S. (2007): Critical review of heat transfer characteristics of nanofluids. - Renewable and Sustainable Energy Reviews, vol.11, pp.512-523.

[6] De P., Mondal H. and Bera U.K. (2014): Influence of nanofluids on magnetohydrodynamic heat and mass transfer over a non-isothermal wedge with variable viscosity and thermal radiation - Journal of Nanofluids, vol.3, pp.1-8. 
[7] Albadr J., Tayal S. and Alasadi M. (2013): Heat transfer through heat exchanger using $\mathrm{Al}_{2} \mathrm{O}_{3}$ nanofluid at different concentrations. - Case Studies in Thermal Engineering, vol.1, pp.38-44.

[8] Mirmasoumi S. and Behzadmehr A. (2008): Effect of nanoparticles mean diameter on mixed convection heat transfer of a nanofluid in a horizontal tube. - Int. J. of Heat and Fluid Flow, vol.29, No.2, pp.557-566.

[9] Yu W. and Choi S.U.S. (2003): The role of interfacial layers in the enhanced thermal conductivity of nanofluids: a renovated Maxwell model. - Journal of Nanoparticle Research, vol.5, pp.167-171.

[10] Nandy P., Wilfried R. and Das S.K. (2003): Natural convection of nano-fluids. - Heat and Mass Transfer, vol.39, pp.775-784.

[11] Devi A.S.P. and Kandasamy R. (1999): Effects of chemical reaction heat and mass transfer on laminar flow along a semi infinite horizontal plate. - Heat and Mass Transfer, vol.35, pp.465-7.

[12] Devi A.S.P. and Kandasamy R. (2002): Effects of chemical reaction, heat and mass transfer on non-linear mhd laminar boundary layer flow over a wedge with suction and injection. - Int. Comm. Heat Mass Transfer, vol.29, pp.707-716.

[13] Chamkha A. (2003): MHD flow of uniformly stretched vertical permeable surface in the presence of heat generation/absorption and a chemical reaction. - Int. Comm. Heat Mass Transfer, vol.30, pp.413-422.

[14] Fairbanks D.F. and Wike C.R. (1950): Diffusion and chemical re-action in an isothermal laminar flow along a soluble flat plate. - Ind. Eng. Chem. Res., vol.42, pp.471-5.

[15] Fan J.R., Shi J.M. and Xu X.Z. (1998): Similarity solution of mixed convection with chemical reaction over a horizontal moving plate. - Acta Mech., vol.126, pp.59-69.

[16] Ibrahim S.Y. and Makinde O.D. (2010): On MHD boundary layer flow of chemically reacting fluid with heat and mass transfer past a stretching sheet. - Int. J. Fluid Mech., vol.2, pp.123-32.

[17] Rajeswari R., Jothiram B. and Nelson V.K. (2009): Chemical reaction, heat and mass transfer on nonlinear MHD boundary layer flow through a vertical porous surface in the presence of suction. - Applied Mathematical Sciences, vol.3, No.50, pp.2469-2480.

[18] Kandasamy R., Perisamy K. and Sivagnana Prabhu K.K. (2005): Chemical reaction, heat and mass transfer on MHD flow over a vertical stretching surface with heat source and thermal stratification effects. - Int. J. Heat Mass Transfer, vol.48, pp.4557-4561.

[19] Mansour M.A., EI-Anssary N.F. and Aly A.M. (2008): Effects of chemical reaction and thermal stratification on MHD free convective heat an mass transfer over a vertical stretching surface embedded in a porous media considering Soret and Dufour numbers. - Che. Engg. Journal, vol.145, pp.340-5.

[20] Mingchun L., Yusheng W., Yanwen T. and Yuchun Z. (2007): Non thermal equilibrium model of the coupled heat and mass transfer in strong endothermic chemical reaction system of porous media. - Int. J. Heat Mass Transfer, vol.50, pp.2936-2943.

[21] Patil P.M., Chamkha A.J. and Roy S. (2012): Effects of chemical reaction on mixed convection flow of a polar fluid through a porous medium in presence of internal heat generation. - Meccanica, vol.47, pp.483-499.

[22] Patil P.M. (2013): Chemical reaction effects on free convective flow of a polar fluid from a vertical plate with uniform heat and mass fluxes. - IOSR Journal of Mathematics, vol.6, No.5, pp.66-85.

[23] Schlichting H. (2000): Boundary Layer Theory. - New York: Springer.

[24] Lee S.L., Chen T.S. and Armaly B.F. (1987): Mixed convection along vertical cylinders and needles with uniform surface heat flux. - ASME J. Heat Transfer, vol.109, pp.711-716.

[25] Chang C.L. and Lee Z.Y. (2008): Free convection on a vertical plate with uniform and constant heat flux in a thermally stratified micropolar fluid. - Mechanics Research Communications, vol.35, pp.421-427.

Received: May 5, 2018

Revised: August 16, 2018 